\title{
Enhancing sustainable infrastructure with the aid of the Green Infrastructure Toolkit
}

\author{
S. H. Saroop \& D. Allopi \\ Durban University of Technology, South Africa
}

\begin{abstract}
It is globally acknowledged that there is a growing need for co ordination of design, sustainability, economic and environmental requirements of infrastructure projects.

The provision of civil infrastructure plays a major role on the natural environment and on the quality of life.

The lack of appropriate tools and skills for sustainable design is often quoted as a barrier to sustainable design Richardson et al. (Design and Sustainability: A Scoping Report for the Sustainable Design Forum, 2005).

A systematic and iterative analysis of the environmental impact of various design solutions is commonly suggested for infrastructure projects, but rarely happens.

In order to stay competitive and to meet upcoming stricter environmental regulations and customer requirements, designers have a key role in designing civil infrastructure so that it is environmentally sustainable. These and other factors have compelled the engineer to design with greater care and in more detail. The changing roles of engineers will be highlighted, in order to react to changes in climate.

In the area of sustainability, there is an urgent need to apply technologies and methods that deliver better and more sustainable performance in a way that is cost effective.

Sustainability, adaptive and mitigative approaches to climate change, in the design of infrastructure are therefore important steering elements (FIDIC, State of the World Infrastructure Report 2009). This paper discusses the application of 'green technology' on infrastructure design projects. It gives an overview of the proposed Green Township Infrastructure Design Toolkit and looks at a number of recommended green practices on infrastructure services design, that are environmentally sound, placing fewer burdens on the environment.
\end{abstract}


The use of the proposed model would ensure a sustainable design of township infrastructure services through the consideration of scare resources and ecological sensitivity in the design and planning of infrastructure projects.

Keywords: green technology, infrastructure design, eco-efficiency, sustainable development, green infrastructure.

\section{The need to implement green technology on civil engineering infrastructure projects}

Civil engineering projects can have significant site-specific and cumulative impacts on ecological and social systems if not correctly planned, designed and implemented.

In the area of sustainability, there is an urgent need to apply technologies and methods that deliver better and more sustainable performance in a way that is cost effective. Sustainability, adaptive and mitigative approaches to climate change, in the design of infrastructure are therefore important steering elements (FIDIC [2]).

Relatively few designers have as yet explored the transformative potential of ecological design and have preferred to remain apolitical and unconcerned with the distributional impacts of design as they affect the health of humans and ecosystems (Van Wyk [3]).

Infrastructure development has been focused mainly on financing issues and engineering aspects in the region. Mainstreaming environmental aspects and incorporating the eco-efficiency concept into various stages of infrastructure development have not been considered as much as they should have been.

Infrastructure elements such as roads, water, sewage and stormwater can result in loss of critical ecosystems and biodiversity. There is a need to create an eco sensitive infrastructure design rating system that encourages and promotes the use of "softer" design solutions.

The rating of green buildings evaluates the environmental impacts of buildings but with little emphases on the environmental performance of civil engineering infrastructure. The proposed research uses the concept of the green rating of green buildings and creates a decision toolkit that assesses the environmental impacts of infrastructure design decisions on development.

By utilising improved environmentally friendly-seeking design solutions, this study aims to introduce environmentally friendly design decisions prior to the infrastructure design approval process. This increases overall competitiveness by bringing a whole new class of productive solutions to problems while at the same time adding a fresh perspective to the traditional infrastructure design process.

Diligent attention to greener infrastructure solutions from the very earliest phases of a project will help guarantee that quality design environmental solutions are "built in" from the beginning. Figure 1 shows the declining influence of environmental interventions on a project. It is important to implement the environmental management from the early stages of the process, since the "freedom" to make decisions, of importance for the environment, decreases with the progress of the project. 


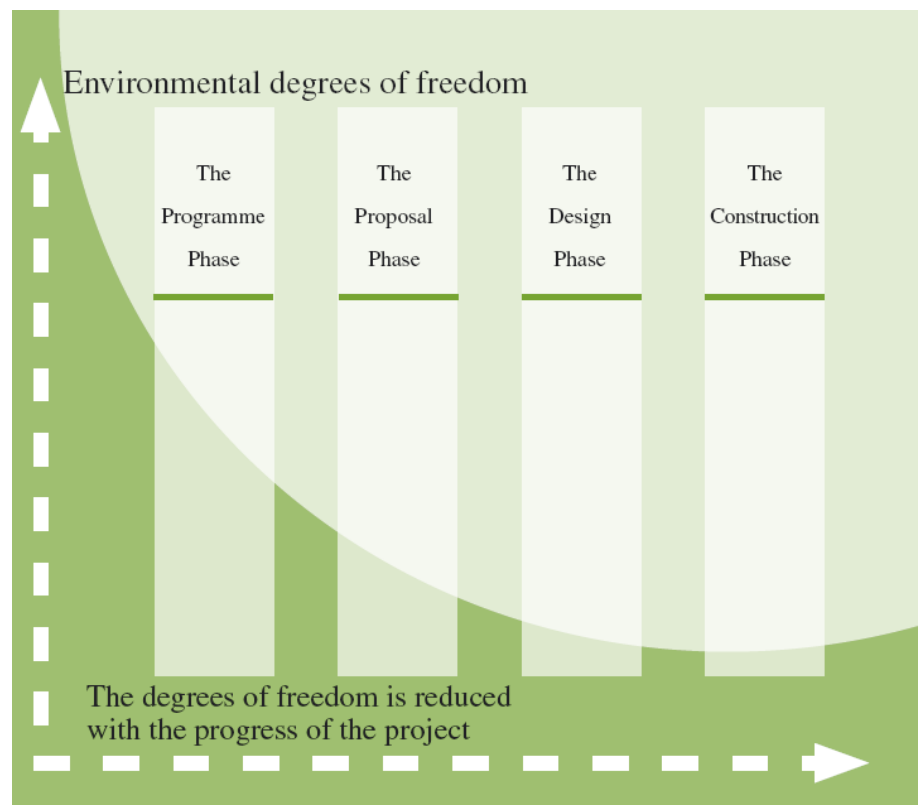

Figure 1: The environmental degrees of freedom (European green cities network [4].

\section{Infrastructure environmental sustainability criteria}

Environmental Sustainability criteria are the set of performance measures that characterize sustainable criteria of infrastructure as listed in Table 1.

The Eco Efficient Infrastructure Sustainability Criteria namely Efficient Layout Planning ensures that infrastructure is placed in environmentally responsible ways. The Resources criteria encourage an efficient utilisation of materials/ resources. Environmental Quality mitigates environmental impacts of infrastructure. Functional Efficiency ensures that infrastructure is designed optimally. Future Maintenance maximizes the opportunities for integrating capital and operation of infrastructure. Economy maximizes the opportunities for integrated cost effective adoption of green infrastructure options. Safety minimises the environmental impact of infrastructure by incorporating safety into the design and convenience provide a range of mobility choices and accessibility options for infrastructure

The Infrastructure Sustainability criteria used in the proposed Green Township Infrastructure Design Toolkit were developed to:

- Determine the means by which eco- environmental efficiency can be assessed, monitored, quantified and verified at any stage of the project, to ensure a value-added, quality driven, green approach to infrastructure design; 
- Provide a basis for the consultants and clients to work together on creating and evaluating sustainable infrastructure solutions thereby ensuring comprehensive infrastructure planning with maximum stakeholder involvement;

- Achieve the required balance of sustainability, expenditure, value for money and quality, between the various elements of the project;

Table 1: $\quad$ The eco efficient infrastructure performance criteria.

\begin{tabular}{|l|l|}
\hline $\begin{array}{c}\text { Eco-efficient } \\
\text { infrastructure } \\
\text { Sustainable } \\
\text { criteria }\end{array}$ & \multicolumn{1}{c|}{ Measure } \\
\hline $\begin{array}{l}\text { 1. Efficient } \\
\text { Layout planning }\end{array}$ & $\begin{array}{l}\text { Placement of infrastructure in environmentally } \\
\text { responsible, efficient ways, conserve land, }\end{array}$ \\
\hline 2. Resources & $\begin{array}{l}\text { Encourages the efficient utilisation of materials/ } \\
\text { resources, selection of environmentally friendly } \\
\text { materials, }\end{array}$ \\
\hline $\begin{array}{l}\text { 3. Environment } \\
\text { quality }\end{array}$ & $\begin{array}{l}\text { Design features that mitigate environmental impacts } \\
\text { of infrastructure, by reducing effects of pollutants }\end{array}$ \\
\hline $\begin{array}{l}\text { 4. Functional } \\
\text { efficiency }\end{array}$ & $\begin{array}{l}\text { Design of infrastructure that maximizes functional } \\
\text { efficiency of infrastructure }\end{array}$ \\
\hline $\begin{array}{l}\text { 5. Future } \\
\text { maintenance }\end{array}$ & $\begin{array}{l}\text { Maximizes the opportunities for integrating capital } \\
\text { and operation of infrastructure, ensuring reliability of } \\
\text { level of service }\end{array}$ \\
\hline 6. Economy & $\begin{array}{l}\text { Maximizes the opportunities for integrated cost } \\
\text { effective adoption of green infrastructure options }\end{array}$ \\
\hline 7. Safety & $\begin{array}{l}\text { Minimizes the environmental impact of infrastructure } \\
\text { by incorporating safety into the design }\end{array}$ \\
\hline 8. Convenience & $\begin{array}{l}\text { Provide a range of mobility choices and accessibility } \\
\text { options for infrastructure }\end{array}$ \\
\hline
\end{tabular}

\section{The Green Township Infrastructure Toolkit: a green rating system on infrastructure projects}

This paper proposes a toolkit that enforces environmentally sustainable design on township infrastructure services by integrating a consideration of resources, the environment, ecologically sensitive innovative design, maintenance and recyclable materials, from the early design stages of a project.

The Green Township Infrastructure Design Toolkit, as illustrated in Figure 2, uses the concept of eco-efficiency and would allow the designer to evaluate design options, enabling him/her to choose the one likely to yield the best performance with the least environmental impact, based on proven technology. 


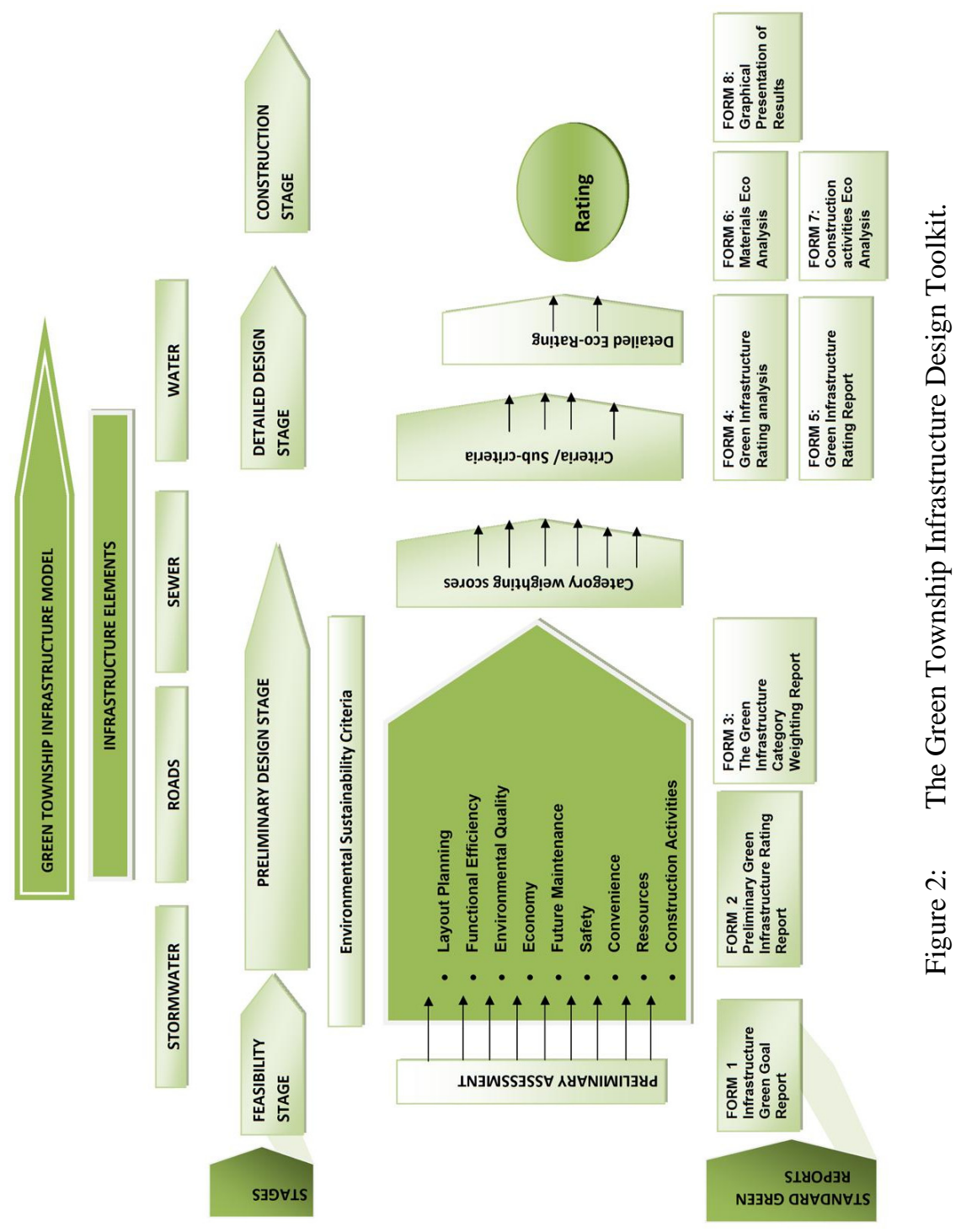


This toolkit is intended to encourage developers to consider green methods and practices in the earliest stages of project planning, by assessing a number of recommended green practices and its environmental impacts on infrastructure services design, placing fewer burdens on the environment.

The various Green Report Forms, enables the client to select a combination of alternatives and evaluate a number of possible design options - with their environmental implications - at each stage of the design process

During the briefing and preliminary design stage, (1 and 2), the client and engineer have a joint responsibility of deciding just how green the project should be, or alternatively of deciding what environmental quality of services can be provided. During the detailed stages (3), the engineer has the responsibility of designing, while maximising the green value of the project. Stage 4 gives the designers an opportunity to add environmental value at the construction stage, by analysing eco-friendly construction material.

The underlying structure of the Green Township Infrastructure Design Toolkit is based on a hierarchical breakdown of the project into five stages described in Table 2 below:

The various green reports developed for use at different stages of the project, provide clients and consultants with more control over the environmental impact of design decisions taken and enable a comparison of the options of various engineering solutions.

Table 2: $\quad$ Stages in the Green Township Infrastructure Design Toolkit.

\begin{tabular}{|l|l|l|}
\hline \multicolumn{2}{|c|}{ Stage } & Activities \\
\hline Stage 1 & Feasibility Stage & Establishing environmental objectives \\
\hline Stage 2 & Scheme Design Stage & Preliminary eco rating \\
\hline Stage 3 & $\begin{array}{l}\text { Preliminary Design } \\
\text { Stage }\end{array}$ & $\begin{array}{l}\text { Weighting of environmental } \\
\text { sustainability categories and targets }\end{array}$ \\
\hline Stage 4 & Detailed Design Stage & Detailed eco rating analysis \\
\hline Stage 5 & Construction Stage & $\begin{array}{l}\text { Materials and construction activities } \\
\text { eco analysis }\end{array}$ \\
\hline
\end{tabular}

\section{Advantages of using the eco approach to infrastructure design}

Green township infrastructure technologies will contribute to greenways and green corridors and provide linkages between habitats, and wetlands. Green technologies have a number of environmental, economic benefits and community benefits. The benefits of this approach are as follows:

- $\quad$ Conservation of natural resources;

- Reduces the ecological footprints of roads, sewer, stormwater and water, allowing ecosystems to function more naturally;

- Uses energy-efficiency systems and materials; 
- Minimizes impervious surfaces reducing soil erosion;

- Enhance and protect ecosystems and biodiversity;

- Conserves and reuses water and treats stormwater runoff on-site;

- Recharges ground water flow for streams, conserving water supplies.

\section{Conclusions}

Engineers will have to be at the forefront of developments finding innovative solutions to maximise water capture, ensuring conservation of the resource from supply through to distribution, and the issues of innovation, technology, design ensuring environmental impacts are avoided or mitigated. Understanding the context of the environment in which they work is thus essential (Kilian and Gibson [5]).

Improvement in the awareness of eco-efficiency concepts is urgently needed among policy-makers, planners and decision-makers. However, the criteria applicable to, and measures for developing eco-efficient and sustainable infrastructure are yet to be fully identified (United Nations Economic and Social Commission for Asia and the Pacific [6]).

Engineers need to look at greener technologies rather than just using traditional engineering solutions. By using this green approach, sustainable design of township infrastructure services can be achieved by enforcing the consideration of resources, environmental impacts of ecologically sensitive design decisions, innovation, maintenance and materials, at the design stage of a project. As can be seen in this paper, there are numerous opportunities for improving eco-efficiency in infrastructure design. A new paradigm for infrastructure design is required in order to ensure environmental sustainability on infrastructure projects

The weighting and rating of environmental sustainability criteria provide adaptation benefits and also provide the means to measure projects.

Taking a greener approach to infrastructure development not only mitigates the potential environmental impacts of development but makes economic sense as well. By softening the environmental footprint, avoiding waste and finding efficiencies, clients and local governments can increase their long term sustainability.

\section{References}

[1] Richardson, J, Irwin T. and Sherwin C. 2005. Design \& Sustainability: A Scoping Report for the Sustainable Design Forum. [online]. Available at: http://webarchive.nationalarchives.gov.uk/tna/+/http://www.dti.gov.uk/sust ainability/pdfs/design_and_sustainability_report_June_2005.pdf [Accessed 1 December 2010].

[2] FIDIC, 2009. FIDIC State of the World Infrastructure Report 2009.

[3] Van Wyk, L. 2009. EcoBuilding: Towards an Appropriate Architectonic Expression, In Green Building Handbook for South Africa [online]. 
Available at: http://researchspace.csir.co.za/dspace/bitstream/10204/3262/1 /vanWyk1_2009.pdf [Accessed 13 April 2011].

[4] European Green Cities Network, 2004. Manual and Guidelines for Sustainable Housing Projects. [online]. www.europeangreencities.com/pdf/ publications/manualSustainableHP.pdf [Accessed 1 April 2004].

[5] Kilian D and Gibson D. 2007, Environmental information for decisionmaking, Civil Engineering, August 2007vol 15,8, ISSN 1021-2000.

[6] United Nations Economic and Social Commission for Asia and the Pacific. 2006. Sustainable Infrastructure in Asia [online]. http://www.unescap.org/esd/environment/mced/singg/documents/Sustainab le Infrastructure in Asia.pdf [Accessed 1 April 2010]. 